\title{
Value of analysts' consensus recommendations and investor sentiment
}

\author{
Pilar Corredor, Elena Ferrer, and Rafael Santamaría \\ Universidad Pública de Navarra (SPAIN)
}

Corresponding author:

Rafael Santamaria. Dpt. Gestion de Empresas. Universidad Publica de Navarra. Campus de Arrosadia s/n 31008 Pamplona (SPAIN). Ph. 34 948169389. E-mail: rafael@unavarra.es

Coauthors:

Pilar Corredor. Dpt. Gestion de Empresas. Universidad Publica de Navarra. Campus de Arrosadia s/n 31008 Pamplona (SPAIN). Ph. 34 948169380. E-mail: corredorp@unavarra.es

Elena Ferrer. Dpt. Gestion de Empresas. Universidad Publica de Navarra. Campus de Arrosadia s/n 31008 Pamplona (SPAIN). Ph. 34 948169408. E-mail: elena.ferrer@unavarra.es

\section{ACKNOWLEDGEMENTS}

This paper has received financial support from the Spanish Ministry of Science and Innovation (ECO2009-12819). We would like to thank the anonymous referee for valuable comments. 


\title{
Value of analysts' consensus recommendations and investor sentiment
}

\begin{abstract}
:
This paper studies the effect of investor sentiment on analysts' consensus recommendations. Our results show that the optimistic bias of analysts in the issuing of recommendations is affected by investor sentiment: the greater the investor sentiment, the more optimistically biased the analysts' consensus recommendations. This bias is larger in stocks whose characteristics make them hard to value or to arbitrage. We also show that investor sentiment can help in the design of profitable strategies, particularly when taking the short position in portfolios with high sentiment sensitivity stocks.
\end{abstract}

KEYWORDS: Investor sentiment. Analysts. Consensus recommendations

\section{INTRODUCTION}

Financial analysts play an important role in financial markets as information intermediaries, issuing recommendations and earnings forecasts that can help investors in their decision-making process (Ke and $\mathrm{Yu}, 2009)$. However, their optimistic bias has brought their objectivity into question ${ }^{1}$. Recent studies do not provide evidence that this bias has been significantly reduced, despite the existence of regulation aimed at correcting it ${ }^{2}$. In fact, Kolasinski (2006) shows that this bias, far from disappearing, has even increased in recent years due to the indirect effect of the regulation itself on the activity of financial analysts.

In this context, the value of the recommendations has been the subject of various studies, primarily in the US market, with mixed results (Barber et al., 2001; Jegadeesh, et al., 2004; Jegadeesh and Kim, 2006; and Balboa et al., 2008 and 2009). However, the possible relationship between the level of consensus recommendations and investor sentiment, as far as we know, has only been studied in Hribar and McInnis (2009) and Bagnoli et al (2009), both of them focused on the US market. Hribar and McInnis

\footnotetext{
1 There is another bias related to the coverage of analysts that has already been studied by Bhushan (1989) who shows that size, ownership structure and the number of lines of business of the company influence the number of analysts that follow a company. Jegadeesh et al (2004) find this bias in glamour stocks, in stocks with a positive momentum and in those with a high turnover.

2 The NASD and NYSE rules 2711 and 472, adopted on July 29, 2002, prohibit analyst participation in equity underwriting deals and prohibit the compensation of analysts from other than underwriting fees.
} 
(2009) apply a correlation analysis and do not find a significant relationship between recommendations and sentiment. In contrast, Bagnoli et al (2009) find that financial analysts issue more optimistic recommendations when recent or past investor sentiment is high. As a consequence, they observe that analysts who are more sensitive to investor sentiment issue less profitable recommendations.

In this context, it is interesting to study this question in depth by analysing some key European markets in order to obtain more robust conclusions. We analyse Germany, France, Spain and the United Kingdom, a selection that allows us to study markets with different market-clearing mechanisms and stock characteristics (size, BTM, liquidity, etc.). These characteristics, in particular those related to the difficulty of valuation and arbitrage, are important because there is broad empirical evidence of the sensitivity of future returns on these stocks to the evolution of investor sentiment (see Baker and Wurgler, 2006 and 2007). These four countries belong to two very different financial systems, the Anglo-Saxon and the Continental systems, ${ }^{3}$ and they show different features with respect to culture dimensions, corporate governance and the quality of the legal environment ${ }^{4}$.

This study basically examines two issues. The first is whether the level of consensus recommendation is/is not affected by investor sentiment. We will focus on analysts' consensus recommendations to observe the importance of this relationship. We must emphasize that, although the paper of Bagnoli et al (2009) is interesting as a complementary analysis ${ }^{5}$, it is necessary to test not only whether the level of consensus recommendation is/is not affected by investor sentiment but also if this relationship is independent of the characteristics of the stocks or whether, as expected, it is higher in stocks that are hard to value or to arbitrage. If we find this relationship, the second

\footnotetext{
${ }^{3}$ Firms belonging to the Continental system show a highly concentrated ownership structure, which promotes stability and commitment although it reduces capital market liquidity. These characteristics make firms based on the Continental model quite different to those based on the Anglo-Saxon model, which is characterized by shareholder dispersion and a wider separation between ownership and control. In terms of institutional investor type, the majority of institutional investors in Continental system are banks, which take an active part in firm management, whereas, in the Anglo-Saxon system, they are mostly mutual funds or pension funds.

${ }^{4}$ Following measures developed by Hoftsede (2001), we observe divergence in herd and overreaction behaviour. For example, the UK is a country with a high degree of individualism, displaying a high uncertainty tolerance, while Spain score higher than the European average for its propensity to act in groups and to avoid uncertainty. The countries selected also have different shareholder and corporate governance structures. La Porta et al. (1998) finds cross-country differences in shareholder and creditor protection, showing that it is stronger in countries governed by common law and weaker in those governed by civil law.

${ }_{5}^{5}$ Note that analysts may be biased towards some kinds of stocks. If this is the case, the relationship found by Bagnoli et al. (2009) may be a simple consequence of the relationship between sentiment and the analysts' coverage.
} 
important issue to explore is the analysis of the value of the consensus recommendations when investor sentiment is taken into account to design strategies. This paper contributes to the literature in several ways. First, we show that analysts' consensus recommendations are significantly affected by investor sentiment in all of the four markets analyzed. Second, we find that this effect is not uniform across stocks, being higher in stocks that are more sensitive to investor sentiment (small, volatile, nondividend payers and with high BTM). This information has allowed the design of investment strategies based on the recommendations of the analysts and taking into account these stock characteristics. In particular, we have compared the risk-adjusted returns obtained by several strategies with different levels of exposure to investor sentiment to the benchmark strategy, which is to follow all the consensus recommendations. Our results show that the risk-adjusted returns of these strategies are significantly greater than the benchmark strategy. These results are robust because they are similar in the four markets analysed

From an academic perspective, this paper sheds light on the value of analysts' consensus recommendations by showing that investor sentiment affects their value and that this effect is not uniform across stocks. From the practitioners' perspective, this paper provides useful information for the implementation of profitable strategies because it is possible obtain abnormal positive returns by employing a combination of the information offered by consensus recommendations and the proxy of investor sentiment.

The remainder of the paper proceeds as follows. Section 2 presents the theoretical framework. Section 3 describes the database and the construction of the proxy of investor sentiment. Section 4 describes analysts' consensus recommendations and the methodology applied. Section 5 analyzes the effect of investor sentiment on analysts' consensus recommendations. Section 6 contains a discussion about the value of analysts' stock recommendations and the profitability of these strategies. Finally, Section 7 outlines the main conclusions of the study

\section{THEORETICAL FRAMEWORK}

The literature has shown the existence of a systematic optimistic bias in analysts' behaviour (see, among others, Brown, 1997; Chopra, 1998 and Easterwood and Nutt, 1999 or, more recently, Kothari, 2001 or Ramnath et al. 2006). On the one hand, there is also a systematic tendency to issue optimistic estimates of the future earnings of firms 
(Chopra, 1998 and Richardson et al., 2004). On the other hand, it is also clearly established that analysts are inclined to give more buying than selling recommendations. An extensive literature has focused on the investment value of analysts' stock recommendations revealing two complementary strands of research. Firstly, studies that examine whether investors can profit from investment strategies involving consensus recommendations and changes in analysts' recommendations (Womack, 1996; Barber et al., 2001 and 2003; and Balboa et al., 2008 and 2009). Secondly, there are some authors who have analyzed the relationship between the characteristics of recommended companies and their value, both consensus recommendations and their changes (Jegadeesh et al., 2004; and Azzi et al. , 2006).

With respect to the first strand, Womack (1996) and Barber et al. (2001) find that a strategy consisting of buying stocks with the most favourable recommendations and selling stocks with more unfavourable consensus recommendations yields positive returns. These results are more pronounced for small firms. Jegadeesh et al. (2004) document that upgraded stocks outperform downgraded stocks. In addition, they find that strategies based on changes in consensus recommendations offer better returns than those based on the level of consensus. These authors, in relation to the second line of study, find that analysts tend to recommend growth stocks, those with a greater momentum and those with a high turnover. These stocks generate higher returns than those that have the opposite characteristics.

Previous evidence is centred on the US market. In an international context, Jegadeesh and Kim (2006) examine the returns generated following the revisions of analysts' recommendations for the G7 countries. Azzi et al. (2006) study 15 European markets, showing the trend of analysts in favour of large firms, stocks with a greater momentum and growth stocks. Azzi and Bird (2005) evaluate Australian analysts and suggest that they attempt to adjust the biases in their recommendations over the market cycle.

Finally, Balboa et al. (2008 and 2009) explore 8 developed stock markets. The first paper documents that sell recommendations seem to be much more useful for providing significant positive returns. At the same time, they note that consensus changes are a valuable tool for investment decisions. In addition, they show that the optimistic bias of analysts influences the value of consensus recommendations portfolios but not the portfolios of change of consensus. In the second paper, they show that the country-bias is an important input for making financial decisions, especially when working with consensus levels. 
The explanations for the detected optimism focus mainly on three aspects: the economic incentives which affect the analysts, the cognitive bias of the analysts and the negative skewness in earnings (see Kothari, 2001 or Qian, 2009)

The first aspect is linked to investment banking businesses and commissions for their brokerage houses, which leads analysts to issue upward-biased recommendations and earnings forecasts (Lin and McNichols, 1998; and Agrawal and Chen, 2008). Michaely and Womack (1999) noted the relationship between brokerage house membership and analysts' forecasts. Das et al. (1998), Lim (2001) and Hong and Kubik (2003) examine the link between the bias in the degree of optimism of analysts and both the development of their careers and their facility of access to non-public information. Irvine (2004) finds that optimistic recommendations generate high trading commissions through the analysts' brokerage firms.

The second aspect relates the bias to analysts' errors when processing information. Overreactions of analysts to good news about earnings, over-valuation due to the existence of speculators or overconfidence in the accuracy of their own information are some of the interpretations offered in the previous literature (Easterwood and Nutt, 1999 or Friesen and Weller, 2006).

In relation to the third aspect, $\mathrm{Gu}$ and $\mathrm{Wu}$ (2003) indicate that the optimism bias may come from analysts attempting to improve the accuracy of their forecasts by taking the observed skewness in earnings into account)

In the above-mentioned connection between the cognitive bias and the optimism of analysts, investor sentiment arises as a possible explanatory factor for the optimism latent in the forecasts and recommendations issued by analysts. Baker and Wurgler (2006, 2007) associate investor sentiment with the propensity to speculate or optimism or pessimism about an stock. The influence of sentiment on future stock returns varies depending on the difficulty of valuation (which would lead to an increased presence of speculative investors) and the difficulty of arbitrage. This implies that sentiment has greater effects on small, young, volatile, non-dividend payers, those with greater growth opportunities and those with higher default risk stocks. As a result, these stocks will be more likely to be affected by states of optimism. Hribar and McInnis (2009) analyze this relationship and incorporate forecast errors as an explanatory element. Their results indicate that errors absorb much of the influence of sentiment on the future stock returns because errors are intermediating variables in the cross-sectional patterns documented between sentiment and stock returns. 
The effect of investor sentiment on stock recommendations has been analyzed by Hribar and McInnis (2009) who apply a correlation analysis and find no significant relationship between sentiment and recommendations. Bagnoli et al (2009), however, find that analysts tend to issue more optimistic recommendations when the recent or past investor sentiment is high. In addition, they try to identify the analysts who are more influenced by sentiment in their forecasts and show that these analysts issue less profitable recommendations.

Following this new stream of research, we analyze the relationship between investor sentiment and consensus recommendations in four key European markets. We also study if this relationship is homogeneous across stocks or whether it depends on characteristics of the stocks related to the difficulty of valuation or arbitrage. Finally, we test whether this connection affects the value of strategies based on analysts' consensus recommendations.

\section{3.-DATABASE}

\subsection{Stock characteristics}

The stock characteristics considered are the book to market ratio (BTM) ${ }^{6}$, size (SIZ), measured as the stock market capitalization of each firm, volatility (VOL), computed as the last twelve months' standard deviation, and the dividend per share ratio (DPS).

The data were obtained from the Datastream (Thomson Financial) database ${ }^{7}$ for four of the key European countries: France (FR), Germany (GE), Spain (SP) and the United Kingdom $(\mathrm{UK})^{8}$. We measure all data in euros, with the exception of the market data of the United Kingdom which is expressed in pounds. Variables related to analysts' stock recommendations, such as the number of recommendations and the different types of

\footnotetext{
${ }^{6}$ We remove stocks with negative book to market values.

${ }^{7}$ In line with Ince and Porter (2006), we have screened and corrected the database. We have removed padded zero-return records at the end of delisted firms, we have removed all nonlocal firms and all listing other than those on the primary exchange and all listing with Type not equal to Equity. We include only those firms that checked YES in the "Primary quote" field. Extremely high monthly returns were removed so that the portfolio monthly returns are no higher than $\pm 10 \%$.

${ }^{8}$ The study focuses on four key markets in Europe that have a wide presence of financial analysts. In this way, it will be possible to make reasonably homogeneous comparisons among stocks in financial markets with a similar degree of development. The reasons for choosing these countries were the availability of data and the search for countries with some differences in their cultural dimensions, their corporate governance and the quality of their legal environment, as well as their belonging to two diverse financial systems: the Anglo-Saxon and continental.
} 
recommendations, are taken from Factset database ${ }^{9}$. The sample period runs from January 1994 to December 2007 because the earliest available recommendations information on Factset is from the end of 1993 and because the Baker and Wurgler index (2006) is publicly available until the end of 2007. The average number of firms covered has a general upward trend. In the first year of our sample, there are, on average, 139 firms from France, 78 from Germany, 33 from Spain and 42 from the United Kingdom whereas, in 2007, the sample includes 407 from France, 328 from Germany, 104 from Spain and 394 from the United Kingdom.

To analyze the effect of sentiment, we sort each monthly return observation according to the quintile rank that the corresponding characteristic takes at the beginning of that month. We expect that analysts' optimism due to high sentiment will be greater in the stocks that are hardest to arbitrage or value (the first size and dividend quintiles and the fifth volatility quintile). Henceforth, these quintiles are defined as high sentiment sensitive (HSS) stocks. In contrast, stocks with characteristics located in the opposite quintiles are defined as low sentiment sensitive (LSS) stocks.

In the case of the BTM ratio, both high growth stocks (first quintile) and high default risk stocks (fifth quintile) may be defined as HSS stocks.

\subsection{Investor sentiment}

The measurement of the sentiment variable varies from one study to another, with researchers drawing on numerous indicators including investor survey findings (Brown and Cliff, 2005, and Lemmon and Portniaguina, 2006), mutual fund flows (Brown et al., 2003; Frazzini and Lamont, 2008), the dividend premium (Baker and Wurgler, 2004a and b), the closed-end fund discount (Zweig, 1973; Lee, et al., 1991; Swaminathan, 1996, and Neal and Wheatley, 1998), turnover or trading volume (Jones, 2001; Sheinkman and Xiong, 2003; and Baker and Stein, 2004), and, more recently, composite sentiment indexes (Brown and Cliff, 2004; Baker and Wurgler, 2006, 2007). In recent papers, the tendency is to construct) global sentiment indexes, which include local sentiment proxies. Baker et al. (2010) construct indices of investor sentiment for six major stock markets and compose them into one global sentiment index. Chang et al. (2011) use the first principal component of US, UK, French and German sentiment

\footnotetext{
9 FactSet presents a potential bias in survival, as well as a selection bias because it collects recommendations and forecasts of the brokerage houses that collaborate voluntarily. It is not possible to correct both biases.
} 
as a measure of global investor sentiment. In this paper, in line with these two studies, we build a global sentiment index. In this way, we have the common component in US and Europe sentiment ${ }^{10}$ as a measure of global investor sentiment.

As a proxy of US sentiment, we use the composite index constructed by Baker and Wurgler (2006) (henceforth, SentUS) and made up of 6 sentiment indicator variables: the closed-end fund discount, stock turnover, number of IPOs and average IPOs firstday returns, the equity share in new issues and the dividend premium ${ }^{11}$.

The European sentiment index (henceforth, SentEU) collects information about the investor sentiment of four key European markets: France (SentFR), Germany (SentGE), Spain (SentSP) and the UK (SentUK). Following the proposals given in Baker and Wurgler (2006) and Baker et al. (2010) we use principal components analysis to isolate the common component. In our case, we build a composite sentiment index of these four markets. Firstly, we obtain four local composite indexes. The variables included in each local sentiment index are: turnover, volatility premium and consumer confidence inde ${ }^{12}$. In line with Baker and Wurgler (2006), we start with the estimation of the first principal components of these three variables and their lags. This gives a first-stage index with six loadings and the variable is included in $\mathrm{t}$ or $\mathrm{t}-1$, depending on which is most highly correlated with the first-stage index. After obtaining the four local composite indexes, they are included in the construction of the European sentiment index. More specifically, the European sentiment index coefficients are as follows:

$\operatorname{SentEU}_{\mathrm{t}}=0.32 * \operatorname{SentFR}_{\mathrm{t}}+0.43 * \operatorname{SentGE}_{\mathrm{t}}+0.34 * \operatorname{SentSP}_{\mathrm{t}}+0.27 * \operatorname{SentUK}_{\mathrm{t}}$

This principal component explains $51.87 \%$ of the total variance.

Finally, as a measure of global sentiment (henceforth, SentG), we form a composite index that captures the common component in the SentUS and SentEU indexes. This first principal factor explains $81.15 \%$ of the sample variance, so we conclude that one factor captures much of the common variation. The resulting index is:

\footnotetext{
${ }^{10}$ Due to lack of data, we exclude the Japanese sentiment index and all other Asian references.

${ }^{11}$ The BW index data are available on the website of Wurgler http://www.stern.nyu.edu/ jwurgler

12 The reason for the consideration of these three variables is their relationship with the level of sentiment. Details of the construction of the volatility premium are available in Baker et al. (2010). Finally, consumer confidence has been used in numerous studies such as Brown and Cliff (2005) and Lemmon and Portniaguina (2006), among others. The index of consumer confidence data come from the website of the European Commission http://ec.europa.eu/economy_finance/db_indicators/surveys/index_en.htm
} 
$\operatorname{SentG}_{\mathrm{t}}=0.55 * \operatorname{SentUS}_{\mathrm{t}}+0.55 * \operatorname{SentEU}_{\mathrm{t}}$

The SentUS and SentEU indexes show a positive and significant correlation (0.65), while the correlation of each of these indexes with the SentG is 0.908 . Note that, each sentiment index is likely to include a sentiment component as well as a common economic cycle component. For this reason, we construct a new global index that explicitly removes the effect of possible changes in the economic cycle ${ }^{13}$.

\section{EMPIRICAL METHODOLOGY}

\subsection{Analysts' consensus recommendations}

The level of consensus of a given stock $s$ in each month $t, C_{s, t}$, is calculated as the arithmetical mean of the last recommendation issued by the analysts following a firm ${ }^{14}$. FactSet classifies recommendations received from brokerage houses on a five point scale. In line with Jegadeesh et al (2004) or Ljungqvist et al. (2006), to allow a more intuitive interpretation of the quantitative results, we code the recommendation as $1=$ sell; 2=underweight; $3=$ hold; 4=overweight; $5=$ buy.

Table I shows the distribution of recommendations by category for each country. The country with the highest monthly mean number of recommendations issued is the United Kingdom, while the country with the lowest number of recommendations per month is France. Nevertheless, we observe that the distribution is positively skewed in the four markets analyzed since positive recommendations (buy and overweight) make up approximately $52 \%$ of the total number and sell/underweight recommendations $17 \%$. Finally, we show the ratio between positive recommendations (buy and overweight) and negative recommendations (sell and underweight) as a proxy of the optimism bias of financial analysts. The UK is the country with the highest bias with analysts issuing approximately 4 positive recommendations for each negative recommendation. Spain is the country with the lowest bias with a ratio of around 2.79. On average, the number of buy recommendations is around 2.79 times that of sell recommendations. These results are close to those obtained by Lee et al. (2004), Jegadeesh and Kim (2006) and Balboa

\footnotetext{
${ }^{13}$ Following Baker and Wurgler (2006) and Schmeling (2009), the macroeconomic variables considered are the index of industrial production, consumption of durable and non-durable goods and the rate of unemployment. The construction of this new index is similar to the previous one. However, the three initial individual measures are orthogonalized on these macroeconomics variables.

14 According to Elton et al. (1986), the level of consensus contains more information than individual recommendations. This variable has the advantage of eliminating the noise of individual recommendations and can be considered a proxy of the prediction ability of analysts as a group.
} 
et al. (2009), and show the tendency of analysts to issue more positive than negative recommendations.

\section{[ INSERT TABLE I]}

As mentioned above, analyst consensus is computed as a weighted average of monthly recommendations issued for each stock $s$ in a given month t. Therefore, a higher value of analyst consensus is associated with a more favourable recommendation, and this represents greater analyst optimism about a given stock in that month. Formally, analyst consensus recommendations are calculated as follows:

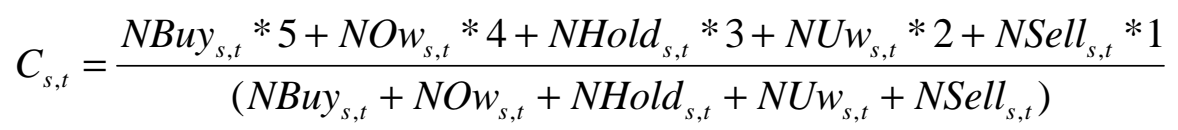

where $N B u y_{s, t}$ is the number of buy recommendations issued for each stock $\mathrm{s}$ in month t, $N O w_{s, t}$ is the number of overweight recommendations, NHold ${ }_{s, t}$ is the number of hold recommendations, $N U w_{s, t}$ is the number of underweight recommendations, and SSell $_{s, t}$ is the number of sell recommendations.

In order to obtain clearer conclusions, we recode analyst consensus recommendations as negative and positive by transforming the variable $\mathrm{C}_{\mathrm{s}, \mathrm{t}}$ into a dichotomous variable 0,1 . At this point, we have to decide whether to include the "hold" recommendation as a negative recommendation or whether not to include it in any group ${ }^{15}$. Initially, we will study both alternatives:

Alternative A (4.A)

$C_{s, t}^{T}=1$ if $C_{s, t}>3$

$C_{s, t}^{T}=0$ if $C_{s, t} \leq 3$
Alternative B (4.B)

$C_{s, t}^{T}=1$ if $C_{s, t}>3$

$C_{s, t}^{T}=0$ if $C_{s, t}<3$

The descriptive statistics of analysts' consensus recommendations using alternative A are shown in Table II. In summary, the results point to the existence of an optimism bias among analysts. This is clearly observed because the monthly average values of

15 The existence of an excess of optimism in the recommendations suggests that the "hold" recommendation should be considered negative, Indeed the results show that this information is negative in the presence of high levels of sentiment because this variable significantly increases the mean value of the consensus recommendation. 
consensus are close to 1 . When the stocks are sorted by characteristics, we can see that HSS stocks have a more unfavourable recommendation than LSS stocks, and this difference is statistically significant ${ }^{16}$. A possible explanation for these results is found in Panel C. Analysts generally tend to recommend LSS stocks, so it is likely that analysts have less pressure or fewer incentives to issue positive recommendations for HSS stocks, so the latter show a lower level of optimism.

\section{[INSERT TABLE II]}

\subsection{Investor sentiment and analysts' consensus recommendations}

To analyze the effect of sentiment on analysts' recommendations, we test the explanatory power of this variable on several portfolios based on the four characteristics discussed earlier. We classify stocks into quintiles according to stock characteristics. As we stated before, stocks are sorted each month by each characteristic and, then, the analysts' consensus recommendations are grouped into quintiles and the average consensus is obtained for the following month.

Taking into consideration the extreme quintiles ( $\mathrm{q}_{1}=$ first quintile and $\mathrm{q}_{5}=$ fifth quintile) for the four countries studied ( $\mathrm{i}=\mathrm{FR}, \mathrm{GE}, \mathrm{SP}$ and $\mathrm{UK}$ ) and according to the stock characteristics ( $\mathrm{j}=\mathrm{BTM}$, SIZ, VOL and DIV), the system of equations to be estimated takes the following form:

$C_{q, t}^{T^{i, j}}=\alpha_{q}^{i, j}+\beta_{q}^{i, j} \operatorname{Sent}_{t-1}^{*}+\gamma_{q}^{i, j} \operatorname{Skew}_{t}^{-}+u_{q, t}^{i, j} ; \quad \mathrm{q}=\mathrm{q}_{1}$ and $\mathrm{q}_{5}$

where $C_{q, t}^{T^{i, j}}$ is the transformed consensus recommendation associated with $\mathrm{q}$ in month $t$, for country $i$ and characteristic $j$. The dependent variable is calculated considering the two alternatives including (A) and not including (B) the "hold" recommendation as a negative recommendation. The independent variables are global sentiment (SentG*), alternatively measured as raw sentiment (SentG) and orthogonal sentiment (SentG $\left.{ }^{\perp}\right)$, and a variable proxy of the skewness in the analysts' recommendations (Skew ${ }^{\perp}$ ), following $\mathrm{Gu}$ and $\mathrm{Wu}$ (2003). Skew ${ }^{\perp}$ is the residual of the following equation:

$$
\operatorname{Skew}_{t}=\lambda_{q}^{i, j}+\phi_{q}^{i, j} \operatorname{Sent}_{t-1}^{*}+\varepsilon_{t}^{i, j}
$$

\footnotetext{
16 The only exception is the UK, where both quintiles in size and dividends are not significantly different.
} 
Finally, an AR(1) model is applied to correct for serial correlation. The system is estimated via GMM to address possible problems of endogeneity ${ }^{17}$. The estimated coefficients are robust to general forms of heteroscedasticity and autocorrelation.

\section{5.- THE EFFECT OF INVESTOR SENTIMENT ON ANALYSTS' OPTIMISM}

The results of the preliminary descriptive analysis have shown, as is widely described in the literature, that analysts are optimistically biased, issuing more positive than negative recommendations. There is also a coverage bias towards LSS stocks.

In this section, we examine the effect of investor sentiment, as a proxy for the overall level of optimism, on the level of consensus recommendations. We also analyze whether this relationship is different in the case of stocks with greater potential sensitivity to investor sentiment (HSS stocks), that is small or volatile stocks and those with a high BTM ratio or low dividend yields.

The results of the estimation of Equation 5, using all the stocks in the case of alternative A (positive recommendation=buy+overweight and negative recommendation=sell +hold+underweight), show that sentiment affects consensus positively and significantly and increases the value of the recommendations. The results are similar when we use the raw sentiment index or the sentiment index orthogonal to the information contained in the macroeconomic variables. This result indicates that the level of optimism in the consensus recommendations is clearly more exaggerated at times of high investor sentiment $^{18}$ (see Panel A of Table III). The skewness in the analysts' recommendations affects the consensus recommendation negatively and significantly and the lagged dependent variable has a significantly positive effect on this variable ${ }^{19}$.

\section{[INSERT TABLE III]}

Panel B of Table III presents the results using all stocks in the case of alternative B: (positive recommendation=buy+overweight and negative recommendation=sell +underweight). These results are quite similar to those in Panel A, although the impact of investor sentiment is lower than in alternative A, which suggests that the "hold"

\footnotetext{
${ }^{17}$ We find endogeneity problems because independent variables are correlated with the residuals of the regression. The instrumental variables used are 3 lags for each of the explanatory variables (the p-value of the test of Hansen of over identifying instruments ranges between 0.30-0. 50)

18 Similar conclusions are obtained if sentiment is proxied by the Baker and Wurgler (2006) index or by the SentUE index. These results are available upon request.

${ }^{19}$ For reasons of clarity, in the tables below, we only include the effect of sentiment. Results from the rest of the data are available upon request.
} 
recommendation, in times of high market sentiment, is very close to a negative recommendation.

Table IV presents the results of the impact of investor sentiment on the consensus recommendations for the two extreme portfolios (HSS and LSS). In this case, the classification criterion is to fulfill, at least, one of the characteristics related to investor sentiment sensitivity ${ }^{20}$. Panel A shows the results of alternative A and Panel B those of alternative B. Our results reveal that investor sentiment has a positive and significant influence on consensus recommendations both in HSS stocks and in LSS stocks. As expected, however, the influence is significantly greater in stocks with characteristics that make them difficult to value and to arbitrage (collected in the HSS quintile). Note that results that do not include the "hold" recommendation as a negative recommendation (alternative B) provide very similar results. The only exception is Spain because, using the measure of alternative B, we do not find significant results.

\section{[INSERT TABLE IV]}

Finally, Table V (Panel A for alternative A and Panel B for alternative B) shows the results of the effect of investor sentiment in more detail, analyzing the four characteristics associated with the sensitivity of stocks to investor sentiment: size, volatility, BTM and dividends. In particular, we analyze the effect of investor sentiment on the two extreme quintiles of each of these characteristics. The first result, in line with our previous results, is that sentiment has a positive and significant effect on consensus recommendations, that is, ceteris paribus, the greater the sentiment, the more positive the recommendation. This effect is significantly higher for HSS stocks.

Analysis by individual stock characteristics allows to offer a more detailed picture. In particular, when using stock size, smaller stocks show a greater effect of sentiment than larger ones. This effect is significant for all countries using alternative $\mathrm{A}$ and for Germany and Spain using alternative B. The analysis of volatility with alternative A indicates the greater effect of sentiment in the most volatile stocks while the UK, using global sentiment, and Spain, using orthogonal sentiment, do not yield significant results. With alternative B, however, only Germany and Spain offer different results between more and less volatile stocks. The results with respect to book-to-market ratio are similar with both alternatives $\mathrm{A}$ and $\mathrm{B}$, being higher in assets with greater book-tomarket, with the exception of France for which the differences are not significant.

\footnotetext{
${ }^{20}$ To impose the fulfillment of two or more features together notably reduces the sample and does not allow us to obtain reliable estimations.
} 
Finally, the results using dividend per share show that stocks with a lower dividend per share present a greater impact of sentiment than stocks with a higher dividend per share. The exception, in this case, is the UK because it is only significant using the measure of alternative A and global sentiment.

\section{[INSERT TABLE V]}

Therefore, two important conclusions can be drawn from these results. The first is that the level of general optimism, proxied by global sentiment, has a significant influence on analysts' consensus recommendations. Analysts are not able to isolate themselves from the general sentiment of optimism, despite the great importance of their role in financial markets. The second important conclusion is that the influence of investor sentiment on consensus recommendations is greater in stocks whose characteristics make them harder to value or to arbitrage (HSS). This indicates that the influence of investor sentiment on the prices of stocks (see Baker and Wurgler, 2006) may be transferred to analysts' estimations and, in this way, generates a significant bias in the level of consensus recommendations.

At this point, we would like to emphasize two additional aspects. The first is that the comparison of alternatives $\mathrm{A}$ and $\mathrm{B}$ indicates that the impact of investor sentiment is higher when the "hold" recommendation is considered as a negative recommendation in the four markets analyzed. These results occur both for the market as a whole as well as for stocks more or less sensitive to investor sentiment (HSS and LSS, respectively), which may be because, as we pointed out, in periods of high sentiment, this strategy has a more negative than neutral character. Thus, the inclusion of the "hold" recommendation together with the other negative recommendations (sell and underweight) does not diminish the impact of sentiment on recommendations. In fact, this alternative can even strengthen the conclusions. Note that, because of the small percentage of strictly negative recommendations (sell and underweight), the inclusion of the "hold" recommendation gives a greater number of observations for the development of different strategies, especially when we take stock characteristics into account.

The second additional aspect is related to the adjustment or not of the sentiment index to the information included in the macroeconomic variables. As the results obtained are basically identical, we will use the raw global sentiment index for the rest of the paper. 


\section{VALUE OF ANALYSTS' CONSENSUS RECOMMENDATIONS: THE ROLE OF SENTIMENT}

Empirical evidence has shown that it is possible to implement profitable strategies based on consensus recommendations (see Jegadeesh, et al. 2004, Jegadeesh and Kim, 2006 and Balboa et al. 2008 and 2009 ${ }^{21}$ ). Recently, Bagnoli et al. (2009) incorporate the role of investor sentiment and show that recommendations that are more correlated with investor sentiment are less profitable, so analysts who wish to maximize the value of their recommendations should pay attention to fundamentals such as benefits, cash flows or discount rates. Given that Bagnoli et al (2009) do not differentiate between positive and negative recommendations and they do not study the potential impact of stock characteristics on their results, in this section, we present the results we have obtained for the strategies based on analysts' consensus recommendations. We adopt a 1-month calendar time approach.

First, we study the effect of investor sentiment on several portfolios of recommendations during the month following their issuance. We classify the stocks according to the type of recommendation, positive or negative, and then we compute the average return of the stocks of each portfolio in the next month ${ }^{22}$. The classification and subsequent formation of the portfolios is carried out each month to obtain a time series of returns. In addition, we include a filter linked to the level of sensitivity of the stocks to investor sentiment by defining high sentiment sensitivity (HSS) stocks by using three criteria. The first is exclusively related to volatility, identifying the stocks of the fifth quintile as HSS stocks and those belonging to the first quintile as LSS stocks. This characteristic, according to the results in the last section, is the one most related to the effect of investor sentiment on the consensus recommendations. The second criterion identifies the stocks that fulfill at least one of the characteristics associated with sentiment sensitivity (stocks in the first quintile of size, in the first quintile of dividend payment, in the fifth quintile of $\mathrm{BTM}^{23}$ or in the fifth quintile of volatility). Finally, the third criterion identifies HSS stocks as those that fulfill the criterion associated with

\footnotetext{
21 Balboa et al. (2009) adjust the recommendation bias for each of the countries they analyze. Their adjustment takes into account the differences across countries as well as the variations in time to correct for the changes in bias over time within countries. In this paper, we do not include this adjustment because investor sentiment has effects not only according to the country but also because of stock characteristics (see Corredor et al. 2011). In fact, this procedure may eliminate part of the impact of sentiment on consensus recommendations, the study of which is the main objective of this paper.

${ }^{22}$ The results using 3 months of holding period offer the same conclusions.

${ }^{23}$ The first quintile of BTM stocks are, along with the largest, the most followed by the analysts.
} 
volatility (fifth quintile of volatility), as well as, at least, one additional characteristic (the first quintile of size, the first quintile of dividend payment or the fifth quintile of $\mathrm{BTM})^{24}$.

Before analyzing the value of the analysts' consensus recommendations taking into account the effect of sentiment on these recommendations, we will analyze whether sentiment affects the return on the portfolios based on consensus recommendations and, more specifically, whether this effect differs depending on the stock characteristics.

In order to analyze the effect of investor sentiment on the portfolios based on recommendations, we estimate the following regression by using the OLS procedure with the Newey and West (1987) standard errors:

$$
R_{c t}-r_{f t}=\alpha_{C}+\beta_{c} \operatorname{Sent} G_{t-1}+\varepsilon_{c t}
$$

where $R_{c t}$ is the return of portfolio $C$ in month $t, r_{f t}$ is the risk-free interest rate ${ }^{25}$ and SentG is the global investor sentiment. The results are shown in Table VI. The portfolios studied are those associated with positive and negative recommendations for each of the groups classified according to the proxy related to the sensitivity of the stocks to investor sentiment. Our results show that investor sentiment explains almost all of the portfolios analyzed negatively and significantly. Only in the case of Spain, although they have a negative sign, are some of them not significant.

\section{[INSERT TABLE VI]}

At this point, it is important to analyze whether the impact is indifferent to the type of stock that makes up the portfolio. It is reasonable to assume that portfolios containing HSS stocks will show a greater coefficient in Equation 7. Table VI collects the results of the Wald test for the null hypothesis of equality of coefficients of positive/negative recommendations for HSS stock portfolios against their respective coefficients for LSS stock portfolios. This test has been applied to the three criteria used to measure the degree of sensitivity of the stocks previously mentioned. The results confirm our arguments. When the first criterion (volatility) is used, 3 of the 4 markets offer a clear

\footnotetext{
${ }^{24}$ An alternative solution could be to impose the joint fulfillment of at least two features. However, given the coverage bias of the recommendations in some variables relevant to the classification, such as size, this solution produces portfolios with very few observations, so they are very sensitive to the potential outliers.

${ }^{25}$ To obtain a homogeneous risk-free interest rate for the whole period and the four markets considered, our reference is the Maastricht Criterion Bond Yield (MCBY), published by EUROSTAT and based on the return rate for the ten-year bond secondary market.
} 
rejection of the null hypothesis of a greater coefficient in the portfolios that contain HSS stocks. Only in the case of the Spanish market, is it not possible to reject this hypothesis at a $10 \%$ significance level, although it could be rejected at a $12 \%$ significance level. When the second criterion is used (the fulfillment of at least one characteristic), the results are less clear as we can only reject the null hypothesis in the French market. However, it is possible that some of the features of this criterion, due to the low number of observations ${ }^{26}$, can produce outliers that make it hard to obtain clearer results. When the third criterion is used (volatility and, at least, one other characteristic), the results are again clear and the null hypothesis is rejected at the $10 \%$ level of significance in 3 of the 4 markets analyzed.

Having observed the effect of investor sentiment on consensus recommendations, we will now study the individual results of the positive and negative recommendations for each of the cases analyzed. Our aim is to evaluate the performance of the portfolios using the Fama and French (1993) multifactor model:

$$
R_{c t}-r_{f t}=\alpha_{c F F}+\beta_{c}\left(R_{M t}-r_{f t}\right)+s_{c} S M B_{t}+h_{c} H M L_{t}+\varepsilon_{c t}
$$

where $R_{c t}$ and $r_{f t}$ are the same as those used in the Equation $7, R_{m t}$ is the market portfolio return and $\mathrm{SMB}_{\mathrm{t}}$ and $\mathrm{HML}_{\mathrm{t}}$ are the factors that capture the effects of size and book to market, both of them created for each market analyzed ${ }^{27}$. The constant $\alpha$ is the risk-adjusted average return.

The results are shown in Table VII. According to previous literature, the positive and negative recommendations (especially the latter) contain important information because they offer significant risk-adjusted returns. The only exception in our results is the Spanish market for which recommendations are not significant at conventional levels, although the negative ones are significant at the $14 \%$ level of significance. However, the most interesting results are obtained when the role of the stocks' characteristics, with respect to their sensitivity to investor sentiment, is taken into account. Using the first criterion, the profitability of the positive recommendations is greater in LSS stocks. Nevertheless, the negative recommendations on HSS stocks offer greater returns. In

\footnotetext{
${ }^{26}$ Note that some of the characteristics associated with the sensitivity of stocks to investor sentiment are also associated with analysts' coverage bias, so there are two elements that can affect the results. On the one hand, the existence of a smaller number of data can have a significant impact due to the effect of potential outliers. On the other hand, due to the coverage bias, we do not have consensus recommendations in the very HSS stocks. In particular, if analysts only cover medium to big stocks, the first quintile of size will not contain the smallest stocks of the population.

${ }^{27}$ As a proxy for the market return for each county, we use an equally weighted portfolio of all the stocks in the market to ensure that the same criterion is used for all countries. See Fama and French (1993) for further details of the construction of the Size and BTM factors.
} 
fact, negative recommendations show significant returns for the three criteria considered and the four countries analyzed. When we use the second criterion, the recommendations (positive and negative) of HSS stocks have greater risk-adjusted returns than those of LSS stocks. In the case of the third criterion, the portfolios with the highest risk-adjusted returns are the positive recommendations on HSS stocks.

\section{[INSERT TABLE VII]}

In any case, the most interesting conclusion is that the consideration of sentiment offers strategies that yield higher risk-adjusted returns than those in portfolios that do not consider this information.

To analyze this issue in depth, we compare the risk-adjusted returns of self-financed portfolios based on recommendations. The benchmark portfolio takes the long position in stocks with positive recommendations and the short position in stocks with negative recommendations. Against this alternative, we design several self-financed portfolios that take into account the sensitivity of the stocks to investor sentiment. The first portfolio (maximum sentiment exposure portfolio) takes the long position in HSS stocks with a positive recommendation and the short position in HSS stocks with a negative recommendation. The second portfolio (positive skewed portfolio) takes the long position in HSS stocks with a positive recommendation and the short position in LSS stocks with a negative recommendation. The third portfolio (negative skewed portfolio) takes the long position in HSS stocks with a positive recommendation and the short position in LSS stocks with a negative recommendation and, finally, the fourth portfolio (minimum sentiment exposure portfolio) takes the long position in LSS stocks with a positive recommendation and the short position in LSS stocks with a negative recommendation.

Table VIII shows the performance of these portfolios. In addition, the results of the Wald test for the null hypothesis that the risk-adjusted return of each portfolio analyzed is equal to the return of the benchmark portfolio are included.

\section{[INSERT TABLE VIII]}

The results using the first criterion are quite clear. In the case of the maximum sentiment exposure portfolio, the risk-adjusted return is higher than the benchmark portfolio, although its difference is not significant at conventional levels. The riskadjusted return of the positive skewed portfolio is clearly lower than the portfolio benchmark, at least for two of four markets analyzed (and also for Spain at the $12 \%$ level of significance). In the case of negative skewed portfolio, the risk-adjusted return 
is significantly greater than the benchmark portfolio in 3 of the 4 markets analyzed at conventional levels (and also for Spain at the 15\% level of significance). Finally, the minimum sentiment exposure portfolio yields a lower risk-adjusted return than the benchmark portfolio, although this difference is only significant for the UK. Note that, in the four markets analyzed, the negative skewed portfolios present a significantly greater risk-adjusted return than the positive skewed portfolios. However, the difference between the negative skewed portfolio and the maximum sentiment exposure portfolio is only significant in the case of the UK. The reason is that both portfolios take the short position in HSS stocks with a negative recommendation, which is the portfolio that obtains the best individual results, as can be seen in Table VII.

The results using the other two criteria are similar although, in the case of the second criterion, the results of the different tests do not offer significant differences between portfolios, probably due to the high variance of these series. When we use the third criterion, however, the results are closer to those obtained with the first one.

Finally, Table IX presents the ranking of the results of the risk-adjusted returns from several strategies: the benchmark portfolio, the short position in all stocks with a negative recommendation, the short position in HSS stocks with a negative recommendation, as well as the maximum sentiment exposure and negative skewed portfolios. The results are very revealing. These last portfolios are ranked in the first positions when the second criterion is used. The negative skewed portfolio occupies leading positions in the first criterion. Indeed, it is the best strategy in two countries: France and the United Kingdom. However, the most notable result is that the benchmark portfolio occupies between 8th and 10th place and the short position in all stocks with negative recommendations is ranked last in all of the markets analyzed. This suggests that it is important to take into account the effect of investor sentiment on the value of analysts' consensus recommendations. Note that a very important part of the explanation of the return of portfolios which take into account the effect of investor sentiment on the recommendations is linked to the performance of one specific portfolio: the HSS stocks with a negative recommendation. In fact, this strategy is ranked in second place in France and in third place in the UK. Perhaps when investor sentiment is very high, the prices of HSS stocks are far from their fundamentals and, therefore, they have a high probability of short-term reversion. 


\section{CONCLUSIONS}

In this paper, we analyze analysts' consensus recommendations in four key European markets, France, Germany, Spain and the United Kingdom, and show that analysts have a bias towards the issuance of more favourable recommendations. We have also found evidence of a bias in analysts' coverage towards stocks that are large, not very volatile, have a low BTM and yield high dividends.

In addition to these aspects, widely described in the literature, we find that the level of general optimism, proxied by market sentiment, has a significant influence on analysts' consensus recommendations. Therefore, the first conclusion is that analysts are not able to isolate themselves from the general sentiment of optimism, despite the great importance of their role in financial markets. The second important conclusion is that the influence of investor sentiment on the consensus recommendations is greater in stocks whose characteristics make them harder to value or to arbitrage (HSS). This indicates that the influence of investor sentiment on the prices of stocks (see Baker and Wurgler, 2006) may be transferred to analysts' estimations and, in this way, generates a significant bias in the level of consensus recommendations.

This influence has important consequences for the value of consensus recommendations issued. We find that the consideration of investor sentiment offers strategies that yield higher risk-adjusted returns than those obtained in portfolios based on all of the recommendations. In particular, the strategy that takes the long position in LSS stocks with a positive recommendation and the short position n HSS stocks with a negative recommendation or, even, the strategy that takes the long and short positions in HSS stocks with positive and negative recommendations, respectively, offers risk-adjusted returns that exceed the benchmark strategy (long position in all stocks with a positive recommendation and short position in all stocks with a negative recommendation). The simple strategy of taking the short position in HSS stocks with a negative recommendation is, per se, one of the strategies that occupies leading positions among all of the strategies analyzed. Perhaps, when investor sentiment is very high, prices of HSS stocks are far from their fundamentals and, therefore, they have a high probability of short-term reversion.

\section{REFERENCES}

Agrawal, A., and Chen, M. A., (2008): “Do analysts' conflicts matter? Evidence from stock recommendations", Journal of Law and Economics, 51, pp. 503-537. 
Azzi, S., and Bird, R., (2005): "Prophets during boom and gloom, downunder", Global Finance Journal, 15, pp. 337-367.

Azzi, S., Bird, R., Griringhelli, P. and Rossi, E., (2006): "Biases and information in analysts' recommendations: the European experience", Journal of Asset Management, 6, pp. 345-80.

Bagnoli, M., Clement, M., Crawley, M., and Watts, S., (2009): “The profitability of analysts' stock recommendations: What role does investor sentiment play?", Working Paper. (July 3, 2009). Available at SSRN: http://ssrn.com/abstract=1430617.

Baker, M., and Wurgler, J., (2004a): “A catering theory of dividends", Journal of Finance, 59, 3, pp. 1125-1165.

Baker, M., and Wurgler, J., (2004b): "Appearing and disappearing dividends: the link to catering incentives", Journal of Financial Economics, 73, 2, pp. 271-288.

Baker, M., and Wurgler, J., (2006): "Investor sentiment and the cross-section of stock returns", Journal of Finance, 61, 4, pp. 1645-1680.

Baker, M., and Wurgler, J., (2007): "Investor sentiment in the stock market", Journal of Economic Perspectives, 21, 2, pp. 129-151.

Baker, M., Wurgler, J., and Yuan, Y., (2010): "Global, local and contagious investor sentiment", AFA 2010 Atlanta Meetings Paper.

Baker, M., and Stein, J., (2004): "Market liquidity as a sentiment indicator", Journal of Financial Markets, 7, pp. 271-299.

Balboa, M., Gomez-Sala, J. C., and Lopez-Espinosa, G., (2008): "Does the value of recommendations depend on the level of optimism? A country-based analysis", Journal of Multinational Financial Management, 18, pp. 405-426.

Balboa, M., Gomez-Sala, J. C., and Lopez-Espinosa, G., (2009): "The value of adjusting the bias in recommendations: international evidence", European Financial Management, 15, pp. 208-230.

Barber, B., Lehavy, R., McNichols, M., and Trueman, B., (2001): “Can investors profit from the prophets? Security analyst recommendations and stock returns", Journal of Finance, 56, pp. 531-564.

Barber, B., Lehavy, R., McNichols, M., and Trueman, B., (2003): "Prophets and losses: Reassessing the returns to analysts' stock recommendations", Financial Analysts Journal, 59, pp. 88-96.

Brown, L. D., (1997): “Analysts forecasting errors: additional evidence”, Financial Analysts Journal, 53, pp. 81-88. 
Brown, G. W., and Cliff, M. T., (2004): "Investor sentiment and the near-term stock market", Journal of Empirical Finance, 11, pp. 1-27.

Brown, G. W., and Cliff, M. T., (2005): "Investor sentiment and asset valuation", Journal of Business, 78, 2, pp. 405-440.

Brown, S., Goetzmann, W. N., Hiraki, T., Shiraishi, N., and Watanabe, M., (2003): "Investor sentiment in Japanese and U.S. daily mutual fund flows", Working Paper. (March 2002). NYU Working Paper No. FIN-02-011. Available at SSRN: http://ssrn.com/abstract=1294180

Bhushan, R., (1989): "Firm characteristics and analysts following", Journal of Accounting and Economics, 11, pp. 255-274.

Chang, Y. Y., Faff, R., and Hwang, C-Y., (2011): "Local and global sentiment effects, and the role of legal, trading and information environments", Working Paper, http://ssrn.com/abstract=1787700.

Chopra, V. K., (1998): “Why so much error in analysts' earning forecasts?”, Financial Analyst Journal, 54, pp. 35-42.

Corredor, P., Ferrer, E., and Santamaría, R., (2011): "Investor sentiment effect in stock markets: stock characteristics or country-specific factors?”, EFMA Meeting 2011. Braga.

Das, S., Levine, C. B., and Sivaramakrishnan, K., (1998): "Earnings predictability and bias in analysts' earnings forecasts", Accounting Review, 73, pp. 277-294.

Easterwood, J. C., and Nutt, S. R., (1999): "Inefficiency in analysts' earnings forecasts: systematic misreaction or systematic optimism?", Journal of Finance, 54, pp. 17771797.

Fama, E., and French, K., (1993): "Common risk factors in the returns on stocks and Bonds", Journal of Financial Economics, 33, pp. 3-56.

Frazzini, A., and Lamont, O., (2008): "Dumb Money: mutual fund flows and the crosssection of stock returns", Journal of Financial Economics, 88, 2, pp. 299-322.

Friesen, G., and Weller, P. A., (2006): "Quantifying cognitive biases in analyst earnings forecasts", Journal of Financial Markets, 9, pp. 333-365.

Gu, Z., and Wu, J. S., (2003): "Earnings skewness and analyst forecast bias", Journal of Accounting and Economics, 35, pp. 5-29.

Hribar, P., and McInnis, J., (2009): "Investor sentiment and analysts' earnings forecast errors", Woking Paper (March 15, 2011). Management Science (Special Issue on 
Behaviorial Economics and Finance), forthcoming. Available at SSRN: http://ssrn.com/abstract=1452893.

Hofstede, G., (2001): “Culture's consequences: comparing values, behaviors, institutions, and organizations across nations", Sage Publication, Beverly Hills.

Hong, H., and Kubik, J. D., (2003): "Analyzing the analysts: career concerns and biased earnings forecasts", Journal of Finance, 58, pp. 313-351.

Ince, O. S., and Porter, R. B., (2006): "Individual equity return data from Thomson Datastream: Handle with care!", Journal of Financial Research, 29, pp. 463-479.

Irvine, P. J., (2004): “Analysts' forecasts and brokerage-firm trading”, Accounting Review, 79, pp. 125-149.

Jegadeesh, N., Kim, J., Krische, S. D., and Lee, C. M. C., (2004): “Analyzing the analysts: when do recommendations add value?", Journal of Finance, 59, pp. 10831124 .

Jegadeesh, N. and Kim, W., (2006): "Value of analyst recommendations: international evidence", Journal of Financial Markets, 9, pp. 274-309.

Jones, C. M., (2001): “A century of stock market liquidity and trading costs”, Working Paper. (May 23, 2002). Available at SSRN: http://ssrn.com/abstract=313681 or doi:10.2139/ssrn.313681

Ke, B., and Yu, Y., (2009): "Why don't analysts use their earnings forecasts in generating stock recommendations?”, Working Paper (april 21, 2009). Available at SSRN: http://ssrn.com/abstract=1011449.

Kolasinski, A., 2006. Is the Chinese wall too high? Investigating the costs of new restrictions on cooperation between analysts and investment bankers. Working paper, MIT Sloan School of Management.

Kothari, S. P., (2001): “Capital markets research in accounting”, Journal of Accounting and Economics, 31, pp. 105-231.

La Porta, F., López-de-Silanes, F., Shleifer, A., and Vishny, R. W., (1998): "Law and finance", Journal of Political Economy, 106, pp. 1113-1155.

Lee, C., Shleifer, A., and Thaler, R. H., (1991): "Investor sentiment and the closed-end fund puzzle", Journal of Finance, 46, pp. 75-109.

Lee, Y., Liu, Y., and Tai, V., (2004): "Who demand on the brokerage house recommendations?", Working paper, National Chengchi University, Taiwan.

Lemmon, M., and Portniaguina, E., (2006): "Consumer confidence and asset prices: some empirical evidence", Review of Financial Studies, 19, 4, pp.1499-1529. 
Lim, T., (2001): "Rationality and analysts' forecast bias", Journal of Finance, 56, pp. 369-385.

Lin, H., and McNichols, M. F., (1998): “Underwriting relationships, analysts' earnings forecasts and investment recommendations", Journal of Accounting and Economics, 25, pp. 101-127.

Ljungqvist, A., Marston, F., and Wilhelm, W., (2006): "Competing for securities underwriting mandates: banking relationships and analyst recommendations", Journal of Finance, 61, pp. 301-340.

Mikhail, R., and Womack, K., (1999): "Conflict of interest and the credibility of underwriter analyst recommendations", Review of Financial Studies Special 1999, 12, pp. 653-686.

Neal, R., and Wheatley, S. M., (1998): "Do measures of investor sentiment predict returns?", Journal of Financial and Quantitative Analysis, 33, 4, pp. 523-547.

Newey, W. K., and West, K. D., (1987): "A simple, positive semi-definite, heteroskedasticity and autocorrelation consistent covariance matrix", Econometrica, 55, pp. 703-708.

Qian, H., (2009): "Time variation in analyst optimism: an investor sentiment explanation", Journal of Behavioral Finance, 10, pp. 182-193.

Ramnath, S., Rock, S., and Shane, P., (2008): "The financial analyst forecasting literature: a taxonomy with suggestions for further research", International Journal of Forecasting, 24, pp. 34-75.

Richardson, S., Teoh, S. and Wysocki P., (2004): "The walk-down to beatable analyst forecasts: the role of equity issuance and insider trading incentives", Contemporary Accounting Research, 21, pp. 885-924.

Scheinkman, J., and Xiong, W., (2003): "Overconfidence and speculative bubbles", Journal of Political Economy, 111, 6, pp. 1183-1219.

Schmeling, M., 2009 Investor sentiment and stock returns: some international evidence, Journal of Empirical Finance, 16, pp. 394-408.

Swaminathan, B., (1996): "Time-varying expected small firm returns and closed-end fund discounts", Review of Financial Studies, 9, pp. 845-887.

Womack, K. L., (1996): “Do brokerage analysts' recommendations have investment value?, Journal of Finance, 51, pp. 137-167.

Zweig, M. E., (1973): “An investor expectations stock price predictive model using closed-end fund premiums", Journal of Finance, 28, 1, pp. 67-87. 
Table I: Distribution of analysts' consensus recommendations, 1994-2007

\begin{tabular}{rccccccc}
\hline & & \multicolumn{5}{c}{ Recommendations by category } & B/S \\
\cline { 5 - 7 } & NumRec & \%buy & \%ow & \% hold & \%uw & \%sell & Ratio \\
\hline France & 2,586 & 40.71 & 17.07 & 25.05 & 7.34 & 9.83 & 3.51 \\
Germany & 8,989 & 31.44 & 19.29 & 32.46 & 8.17 & 8.64 & 2.92 \\
Spain & 12,965 & 33.60 & 14.42 & 31.17 & 8.34 & 12.47 & 2.79 \\
United Kingdom & 31,064 & 28.99 & 19.76 & 37.28 & 5.75 & 8.22 & 3.79 \\
& & & & & & & \\
Average (all countries) & 13,901 & 33.68 & 17.63 & 31.49 & 7.40 & 9.79 & 3.25 \\
\hline
\end{tabular}

NumRec is the average annual number of recommendations issued by analysts during the period analyzed. We present the percentage of recommendations by category. The BS Ratio is the ratio between number of buy + overweight recommendations and the number of underweight + sell recommendations 
Table II: Descriptive statistics of analysts' consensus recommendations, 1994-2007

Panel A: All the stocks

\begin{tabular}{rcccccc}
\hline \multicolumn{4}{c}{ All period } & \multicolumn{2}{c}{$1994-2000$} & \multicolumn{2}{c}{$2001-2007$} \\
\hline & Mean & Skew & Mean & Skew & Mean & Skew \\
\hline FR & 0.76 & -0.21 & 0.78 & -0.30 & 0.74 & 0.06 \\
GE & 0.64 & -1.61 & 0.57 & -1.10 & 0.70 & 0.34 \\
SP & 0.69 & -0.57 & 0.77 & 0.27 & 0.61 & 0.55 \\
UK & 0.81 & -0.42 & 0.82 & -0.78 & 0.80 & -0.04 \\
\hline
\end{tabular}

Panel B: stock characteristics

\begin{tabular}{rcccccccc}
\hline \multicolumn{1}{c}{ SIZ } & \multicolumn{2}{c}{ VOL } & \multicolumn{2}{c}{ BTM } & \multicolumn{2}{c}{ DPS } \\
\hline FR & Mean & Skew & Mean & Skew & Mean & Skew & Mean & Skew \\
\hline 1Q & 0.51 & 0.14 & 0.77 & -0.27 & 0.81 & -0.11 & 0.65 & -0.03 \\
p-value & 0.84 & 0.08 & 0.63 & 0.10 & 0.65 & 0.57 & 0.72 & 0.29 \\
\hline GE & Mean & Skew & Mean & Skew & Mean & Skew & Mean & Skew \\
\hline 1Q & 0.54 & 0.12 & 0.71 & -1.90 & 0.65 & -1.69 & 0.64 & -0.44 \\
5Q & 0.70 & -1.82 & 0.52 & -0.02 & 0.51 & -0.47 & 0.72 & -1.67 \\
p-value & 0.00 & & 0.00 & & 0.00 & & 0.00 & \\
\hline SP & Mean & Skew & Mean & Skew & Mean & Skew & Mean & Skew \\
\hline 1Q & 0.47 & 0.68 & 0.75 & -0.38 & 0.70 & 0.26 & 0.53 & 0.46 \\
$5 \mathrm{Q}$ & 0.77 & -0.18 & 0.56 & -0.09 & 0.60 & 0.21 & 0.75 & -0.44 \\
p-value & 0.00 & & 0.00 & & 0.00 & & 0.00 & \\
\hline UK & Mean & Skew & Mean & Skew & Mean & Skew & Mean & Skew \\
\hline 1Q & 0.82 & -4.85 & 0.83 & -0.37 & 0.83 & -1.35 & 0.84 & 0.09 \\
$5 Q$ & 0.83 & 0.06 & 0.76 & -0.31 & 0.76 & -0.08 & 0.80 & -0.05 \\
p-value & 0.24 & & 0.00 & & 0.00 & & 0.00 & \\
\hline
\end{tabular}

\begin{tabular}{|c|c|c|c|c|c|c|c|c|}
\hline & SIZ & VOL & BTM & DIV & SIZ & VOL & BTM & DPS \\
\hline \multicolumn{5}{|c|}{ France } & \multicolumn{4}{|c|}{ Spain } \\
\hline $1 Q$ & 1.32 & 11.83 & 11.85 & 6.37 & 2.74 & 12.94 & 14.65 & 7.66 \\
\hline $5 Q$ & 20.62 & 6.50 & 7.02 & 12.34 & 21.14 & 9.14 & 8.01 & 15.99 \\
\hline $\mathrm{p}$-value & 0.00 & 0.00 & 0.00 & 0.00 & 0.00 & 0.00 & 0.00 & 0.00 \\
\hline \multicolumn{5}{|c|}{ Germany } & \multicolumn{4}{|c|}{ United Kingdom } \\
\hline $1 Q$ & 1.20 & 7.68 & 5.88 & 3.64 & 2.59 & 10.04 & 9.18 & 6.03 \\
\hline $5 Q$ & 9.62 & 3.45 & 4.13 & 8.94 & 15.57 & 6.73 & 6.75 & 12.31 \\
\hline $\mathrm{p}$-value & 0.00 & 0.00 & 0.00 & 0.00 & 0.00 & 0.00 & 0.00 & 0.00 \\
\hline
\end{tabular}

France (FR), Germany (GE), Spain (SP) and United Kingdom (UK). Panel A shows the monthly average of the recoded analyst consensus recommendations using the alternative A of all stocks and the monthly average of skewness coefficients. Panel B shows the same information for the extreme quintiles classified according to the stock characteristics: size (SIZ), volatility (VOL), book to market ratio (BTM) and dividend per share ratio (DPS). The p-value reflects the significance level of the Wald test for the null hypothesis of the equality of the coefficients of both extreme quintiles. Panel $\mathrm{C}$ shows the monthly average of the total number of recommendations issued by analysts for each quintile of the stock characteristics. Mean coefficients are multiplied by 100 . 
Table III: Effect of investor sentiment on analysts' consensus recommendations. 1994-2007

Panel A: Alternative A

\begin{tabular}{|c|c|c|c|c|c|c|c|c|c|}
\hline & \multicolumn{2}{|c|}{ SentG } & \multicolumn{2}{|c|}{ SentG $\perp$} & & \multicolumn{2}{|c|}{ SentG } & \multicolumn{2}{|c|}{ SentG $\perp$} \\
\hline & Coef. & p-value & Coef. & p-value & & Coef. & p-value & Coef. & p-value \\
\hline \multicolumn{10}{|c|}{ France } \\
\hline Sent & 2.61 & 0.00 & 2.70 & 0.00 & Sent & 1.64 & 0.00 & 1.64 & 0.00 \\
\hline Skew $\perp$ & -0.13 & 0.00 & -0.13 & 0.00 & Skew $\perp$ & -0.07 & 0.00 & -0.07 & 0.00 \\
\hline $\mathrm{AR}(1)$ & 0.13 & 0.01 & 0.13 & 0.02 & $\mathrm{AR}(1)$ & 0.29 & 0.00 & 0.31 & 0.00 \\
\hline \multicolumn{10}{|c|}{ Germany } \\
\hline Sent & 0.88 & 0.00 & 0.34 & 0.00 & Sent & 0.53 & 0.01 & 0.35 & 0.03 \\
\hline Skew $\perp$ & -0.15 & 0.00 & -0.15 & 0.00 & Skew $\perp$ & -0.09 & 0.00 & -0.09 & 0.00 \\
\hline $\operatorname{AR}(1)$ & 0.11 & 0.01 & 0.11 & 0.00 & $\mathrm{AR}(1)$ & 0.30 & 0.01 & 0.31 & 0.01 \\
\hline \multicolumn{10}{|c|}{ Spain } \\
\hline Sent & 5.92 & 0.00 & 6.09 & 0.00 & Sent & 4.73 & 0.00 & 4.93 & 0.00 \\
\hline Skew $\perp$ & -0.16 & 0.00 & -0.16 & 0.00 & Skew $\perp$ & -0.10 & 0.00 & -0.10 & 0.00 \\
\hline $\mathrm{AR}(1)$ & 0.16 & 0.00 & 0.16 & 0.00 & $\mathrm{AR}(1)$ & 0.39 & 0.00 & 0.39 & 0.00 \\
\hline \multicolumn{10}{|c|}{ United Kingdom } \\
\hline Sent & 2.66 & 0.00 & 2.61 & 0.00 & Sent & 1.47 & 0.00 & 1.63 & 0.00 \\
\hline Skew $\perp$ & -0.08 & 0.00 & -0.09 & 0.00 & Skew $\perp$ & -0.03 & 0.00 & -0.03 & 0.00 \\
\hline $\mathrm{AR}(1)$ & 0.20 & 0.06 & 0.20 & 0.04 & $\mathrm{AR}(1)$ & 0.37 & 0.01 & 0.38 & 0.01 \\
\hline
\end{tabular}

Regression of the analysts' consensus recommendations $\mathrm{C}_{\mathrm{i}, \mathrm{m}}$, computed as the weighted average of issued recommendations and recoded into a dichotomous variable $0,1\left(\mathrm{C}_{\mathrm{i}, \mathrm{m}}\right)$. The independent variables are the global sentiment (SentG) or the global sentiment orthogonal to macroeconomic variables $\left(\right.$ SentG $^{\perp}$ ) and the skewness coefficient orthogonal to the global sentiment (Skew $\left.{ }^{\perp}\right)$. The macroeconomic variables considered are the index of industrial production, consumption of durable and non-durable goods and the rate of unemployment. AR (1) is applied to correct for serial correlation. The system is estimated via GMM. SentG is the composite index that captures the common component in SentUS and SentEU. In PanelA (Alt A), $C_{i, m}^{T}=1$ if $C_{i, m}>3$ and $C_{i, m}^{T}=0$ if $C_{i, m} \leq 3$. In Panel B (Alt B), $C_{i, m}^{T}=1$ if $C_{i, m}>3$ and $\mathrm{C}_{\mathrm{i}, \mathrm{m}}^{\mathrm{T}}=0$ if $\mathrm{C}_{\mathrm{i}, \mathrm{m}}<3$. The coefficients of the impact of global sentiment are multiplied by 100 . 
Table IV: Effect of investor sentiment on analysts' consensus recommendations. HSS and LSS stocks 1994-2007

Panel A: Alternative A

\begin{tabular}{rccccccccccc}
\cline { 2 - 11 } & \multicolumn{4}{c}{ SentG } & \multicolumn{1}{c}{ SentG } \\
\hline & \multicolumn{3}{c}{ HSS } & \multicolumn{2}{c}{ LSS } & Wald & \multicolumn{2}{c}{ HSS } & \multicolumn{2}{c}{ LSS } & Wald \\
\hline FR & 4.62 & 0.00 & 1.24 & 0.00 & 0.00 & 5.24 & 0.00 & 1.41 & 0.00 & 0.00 \\
GE & 3.79 & 0.00 & 0.58 & 0.00 & 0.00 & 4.18 & 0.00 & 0.43 & 0.01 & 0.00 \\
SP & 7.73 & 0.00 & 3.34 & 0.00 & 0.00 & 7.86 & 0.00 & 3.20 & 0.00 & 0.00 \\
UK & 2.61 & 0.00 & 1.53 & 0.00 & 0.01 & 2.60 & 0.00 & 1.85 & 0.00 & 0.05 \\
\hline
\end{tabular}

Panel B: Alternative B

\begin{tabular}{rccccccccccc}
\hline & \multicolumn{4}{c}{ SentG } & \multicolumn{3}{c}{ LSS } & Wald & \multicolumn{2}{c}{ HSS } & \multicolumn{3}{c}{ LSS } & Wald \\
\cline { 2 - 11 }$y$ & \multicolumn{3}{c}{ HSS } & \multicolumn{3}{c}{ LS } & pentG \\
FR & 3.36 & 0.00 & 0.67 & 0.00 & 0.00 & 3.55 & 0.00 & 0.56 & 0.01 & 0.00 \\
GE & 1.99 & 0.00 & 0.81 & 0.00 & 0.01 & 2.25 & 0.00 & 1.07 & 0.00 & 0.01 \\
SP & 1.95 & 0.25 & -5.74 & 0.26 & 0.15 & 2.24 & 0.16 & -4.89 & 0.41 & 0.25 \\
UK & 1.62 & 0.00 & 0.41 & 0.03 & 0.00 & 1.46 & 0.00 & 0.39 & 0.05 & 0.01 \\
\hline
\end{tabular}

Regressions of the analysts' consensus recommendations on the two extreme portfolios (HSS and LSS). In this case, the classification criterion is to fulfill, at least, one of the characteristics related to investor sentiment sensitivity. Analysts' consensus recommendations $C_{i, m}$ is calculated as the weighted average of the recommendations issued and recoded into a dichotomous variable $0,1\left(\mathrm{C}_{\mathrm{i}, \mathrm{m}}^{\mathrm{T}}\right)$. The global sentiment index, SentG, is a composite index that captures the common component in SentUS and SentEU and can alternatively be measured without removing the effect of macroeconomic variables (SentG) or orthogonal to this information $\left(\operatorname{SentG}^{\perp}\right)$. The skewness coefficient is orthogonal to global sentiment (Skew ${ }^{\perp}$ ). The macroeconomic variables considered are the index of industrial production, consumption of durable and non-durable goods and the rate of unemployment. AR (1) is applied to correct for serial correlation. The system is estimated via GMM. The p-value reflects the significance level of the Wald test for the null hypothesis of the equality of the coefficients of both the HSS and LSS portfolios. In Panel A (Alternative A), $\mathrm{C}^{\mathrm{T}} \mathrm{i}, \mathrm{m}=1$ if $\mathrm{C}_{\mathrm{i}, \mathrm{m}}>3$ and $\mathrm{C}_{\mathrm{i}, \mathrm{m}}^{\mathrm{T}}=0$ if $\mathrm{C}_{\mathrm{i}, \mathrm{m}} \leq 3$. In Panel $\mathrm{B}$ (Alternative $\mathrm{B}$ ), $\mathrm{C}^{\mathrm{T}}{ }_{\mathrm{i}, \mathrm{m}}=1$ if $\mathrm{C}_{\mathrm{i}, \mathrm{m}}>3$ and $\mathrm{C}_{\mathrm{i}, \mathrm{m}}=0$ if $\mathrm{C}_{\mathrm{i}, \mathrm{m}}<3$. The coefficients are multiplied by 100 . 
Table V: Effect of investor sentiment on analysts' consensus recommendations by stock characteristics 1994-2007

Panel A: Alternative A

\begin{tabular}{|c|c|c|c|c|c|c|c|c|c|c|}
\hline & \multicolumn{5}{|c|}{ SentG } & \multicolumn{5}{|c|}{ 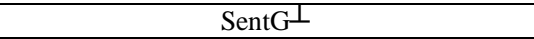 } \\
\hline & \multicolumn{2}{|c|}{ Q1 } & \multicolumn{2}{|c|}{ Q5 } & \multirow{2}{*}{$\frac{\text { Wald }}{\text { p-value }}$} & \multicolumn{2}{|c|}{ Q1 } & \multicolumn{2}{|c|}{ Q5 } & \multirow{2}{*}{$\frac{\text { Wald }}{\text { p-value }}$} \\
\hline & Coef. & p-value & Coef. & p-value & & Coef. & p-value & Coef. & p-value & \\
\hline & \multicolumn{10}{|c|}{ Size } \\
\hline FR & 2.73 & 0.00 & 0.34 & 0.15 & 0.00 & 2.13 & 0.00 & 0.53 & 0.04 & 0.00 \\
\hline GE & -1.79 & 0.00 & 1.10 & 0.01 & 0.00 & -0.45 & 0.41 & 0.85 & 0.01 & 0.04 \\
\hline SP & 7.90 & 0.00 & 2.45 & 0.00 & 0.00 & 7.03 & 0.00 & 2.92 & 0.00 & 0.00 \\
\hline \multirow[t]{2}{*}{ UK } & 1.34 & 0.00 & 0.54 & 0.10 & 0.05 & 1.19 & 0.00 & 0.66 & 0.09 & 0.28 \\
\hline & \multicolumn{10}{|c|}{ Volatility } \\
\hline FR & 1.49 & 0.00 & 5.72 & 0.00 & 0.00 & 2.02 & 0.00 & 4.68 & 0.00 & 0.00 \\
\hline GE & -0.59 & 0.05 & 4.54 & 0.00 & 0.00 & -0.78 & 0.01 & 4.95 & 0.00 & 0.00 \\
\hline SP & 4.51 & 0.00 & 6.10 & 0.00 & 0.10 & 4.93 & 0.00 & 5.96 & 0.00 & 0.29 \\
\hline \multirow[t]{2}{*}{ UK } & 1.53 & 0.00 & 2.41 & 0.00 & 0.13 & 0.91 & 0.05 & 2.39 & 0.00 & 0.03 \\
\hline & \multicolumn{10}{|c|}{ Book to market } \\
\hline FR & 0.25 & 0.44 & -0.11 & 0.79 & 0.46 & 0.43 & 0.25 & 0.14 & 0.72 & 0.56 \\
\hline GE & 0.05 & 0.85 & 1.51 & 0.00 & 0.03 & -0.10 & 0.76 & 1.08 & 0.02 & 0.05 \\
\hline SP & 5.66 & 0.00 & 7.44 & 0.00 & 0.05 & 5.70 & 0.00 & 7.90 & 0.00 & 0.00 \\
\hline UK & 1.42 & 0.00 & 4.14 & 0.00 & 0.00 & 1.22 & 0.00 & 3.77 & 0.00 & 0.00 \\
\hline & \multicolumn{10}{|c|}{ Dividend per share ratio } \\
\hline FR & 3.54 & 0.00 & -0.23 & 0.34 & 0.00 & 3.38 & 0.00 & 0.17 & 0.46 & 0.00 \\
\hline GE & 5.91 & 0.00 & -0.80 & 0.01 & 0.00 & 5.62 & 0.00 & -0.87 & 0.02 & 0.00 \\
\hline SP & 8.73 & 0.00 & 4.80 & 0.00 & 0.00 & 8.57 & 0.00 & 4.69 & 0.00 & 0.00 \\
\hline UK & 1.78 & 0.00 & 0.93 & 0.00 & 0.01 & 1.66 & 0.00 & 1.27 & 0.00 & 0.25 \\
\hline
\end{tabular}

Panel B: Alternative B

\begin{tabular}{|c|c|c|c|c|c|c|c|c|c|c|}
\hline & \multicolumn{5}{|c|}{ SentG } & \multicolumn{5}{|c|}{ SentG $\perp$} \\
\hline & \multicolumn{2}{|c|}{$\mathrm{Q} 1$} & \multicolumn{2}{|c|}{ Q5 } & \multirow{2}{*}{$\frac{\text { Wald }}{\text { p-value }}$} & \multicolumn{2}{|c|}{ Q1 } & \multicolumn{2}{|c|}{ Q5 } & \multirow{2}{*}{$\frac{\text { Wald }}{\text { p-value }}$} \\
\hline & Coef. & p-value & Coef. & p-value & & Coef. & p-value & Coef. & p-value & \\
\hline & \multicolumn{10}{|c|}{ Size } \\
\hline FR & 0.49 & 0.13 & 0.38 & 0.15 & 0.81 & 0.38 & 0.29 & 0.69 & 0.01 & 0.47 \\
\hline GE & 2.55 & 0.00 & 1.12 & 0.07 & 0.03 & 5.42 & 0.00 & 1.14 & 0.07 & 0.00 \\
\hline $\mathrm{SP}$ & 10.68 & 0.00 & 1.60 & 0.00 & 0.00 & 7.88 & 0.00 & 1.80 & 0.00 & 0.00 \\
\hline \multirow[t]{2}{*}{ UK } & 0.85 & 0.00 & 0.43 & 0.23 & 0.33 & 0.93 & 0.00 & 0.45 & 0.22 & 0.27 \\
\hline & \multicolumn{10}{|c|}{ Volatility } \\
\hline FR & 1.31 & 0.00 & 1.50 & 0.13 & 0.85 & 0.88 & 0.13 & 0.52 & 0.56 & 0.71 \\
\hline GE & -0.07 & 0.80 & 4.58 & 0.00 & 0.00 & -0.33 & 0.36 & 3.94 & 0.00 & 0.00 \\
\hline $\mathrm{SP}$ & 1.38 & 0.28 & 4.61 & 0.00 & 0.03 & 1.81 & 0.19 & 4.70 & 0.00 & 0.08 \\
\hline \multirow[t]{2}{*}{ UK } & 0.83 & 0.00 & 0.62 & 0.02 & 0.47 & 1.07 & 0.00 & 0.77 & 0.01 & 0.30 \\
\hline & \multicolumn{10}{|c|}{ Book to market } \\
\hline FR & 0.44 & 0.17 & 0.92 & 0.09 & 0.36 & 0.65 & 0.07 & 0.87 & 0.12 & 0.71 \\
\hline GE & -0.29 & 0.42 & 3.31 & 0.00 & 0.00 & -0.37 & 0.33 & 3.23 & 0.00 & 0.00 \\
\hline SP & 2.62 & 0.07 & 9.69 & 0.00 & 0.00 & 4.28 & 0.00 & 9.11 & 0.00 & 0.00 \\
\hline UK & 0.80 & 0.00 & 1.61 & 0.00 & 0.05 & 0.92 & 0.00 & 1.84 & 0.00 & 0.02 \\
\hline & \multicolumn{10}{|c|}{ Dividend per share ratio } \\
\hline FR & 1.52 & 0.01 & 0.19 & 0.17 & 0.03 & 1.56 & 0.01 & 0.33 & 0.02 & 0.04 \\
\hline GE & 5.30 & 0.00 & 0.33 & 0.36 & 0.00 & 5.91 & 0.00 & 0.29 & 0.41 & 0.00 \\
\hline SP & 6.48 & 0.00 & 0.68 & 0.53 & 0.00 & 5.92 & 0.00 & 2.57 & 0.00 & 0.02 \\
\hline UK & 1.12 & 0.00 & 1.16 & 0.02 & 0.95 & 1.31 & 0.00 & 1.96 & 0.00 & 0.30 \\
\hline
\end{tabular}

France (FR), Germany (GE), Spain (SP) and United Kingdom (UK). Effect of investor sentiment on analysts' consensus recommendations by stock characteristics. Stocks are sorted into quintiles according to their characteristics of size (SIZ), volatility (VOL), book to market ratio (BTM) and dividend per share ratio (DPS). This table shows the extreme quintiles $\mathrm{q}_{1}$ and $\mathrm{q}_{5}$. Analysts' consensus recommendations $\mathrm{C}_{\mathrm{i}, \mathrm{m}}$ is calculated as the weighted average of the recommendations issued and transformed into a dichotomous variable 0,1 . The global sentiment index, SentG, is a composite index that captures the common component in SentUS and SentEU and can alternatively be measured without removing the effect of macroeconomic variables (SentG) or orthogonal to this information (SentG ${ }^{\perp}$ ). The skewness coefficient is orthogonal to global sentiment $(\mathrm{Skew} \perp)$. The macroeconomic variables considered are the index of industrial production, consumption of durable and non-durable goods and the rate of unemployment. AR(1) is applied to correct for serial correlation. The system is estimated via GMM. The p-value reflects the significance level of the Wald test for the null hypothesis of the equality of the coefficients of both the HSS and LSS portfolios. In Panel A (Alternative A), $\mathrm{C}^{\mathrm{T}} \mathrm{i}_{\mathrm{m}}=1$ if $\mathrm{C}_{\mathrm{i}, \mathrm{m}}>3$ and $\mathrm{C}_{\mathrm{i}, \mathrm{m}}^{\mathrm{T}}=0$ if $\mathrm{C}_{\mathrm{i}, \mathrm{m}}$ $\leq 3$. In Panel B (Alternative B), $\mathrm{C}_{\mathrm{i}, \mathrm{m}}^{\mathrm{T}}=1$ if $\mathrm{C}_{\mathrm{i}, \mathrm{m}}>3$ and $\mathrm{C}_{\mathrm{i}, \mathrm{m}}=0$ if $\mathrm{C}_{\mathrm{i}, \mathrm{m}}<3$. The coefficients are multiplied by 100 . 
Table VI: The effect of investor sentiment on positive and negative analysts' consensus recommendations 1994-2007

\begin{tabular}{|c|c|c|c|c|c|c|c|c|}
\hline & \multicolumn{2}{|c|}{ France } & \multicolumn{2}{|c|}{ Germany } & \multicolumn{2}{|c|}{ Spain } & \multicolumn{2}{|c|}{ United Kingdom } \\
\hline & SentG & p-value & SentG & p-value & SentG & p-value & SentG & p-value \\
\hline \multicolumn{9}{|l|}{ All stocks } \\
\hline (1) $\beta_{\text {Pos-all }}$ & -0.85 & 0.07 & -2.61 & 0.00 & -0.37 & 0.28 & -0.53 & 0.14 \\
\hline (2) $\beta_{\text {Neg-all }}$ & -1.12 & 0.02 & -2.55 & 0.00 & -0.30 & 0.37 & -0.52 & 0.24 \\
\hline \multicolumn{9}{|l|}{ First criterion: Volatility } \\
\hline (3) $\beta_{\text {Pos-lss }}$ & -0.70 & 0.02 & -0.91 & 0.02 & -0.42 & 0.21 & -0.43 & 0.11 \\
\hline (4) $\beta$ Pos-hss & -2.17 & 0.02 & -3.57 & 0.01 & -1.11 & 0.09 & -1.62 & 0.01 \\
\hline (5) $\beta_{\text {Neg-lss }}$ & -0.23 & 0.42 & -1.30 & 0.00 & 0.11 & 0.84 & -0.63 & 0.02 \\
\hline (6) $\beta_{\text {Neg-hss }}$ & -3.22 & 0.00 & -3.32 & 0.01 & -0.80 & 0.29 & -1.45 & 0.03 \\
\hline \multicolumn{9}{|c|}{ Second criterion: stocks that fulfill, at least, one of characteristics associated with sentiment sensitivity } \\
\hline (7) $\beta_{\text {Pos-lss }}$ & -0.53 & 0.18 & -2.06 & 0.00 & -0.16 & 0.65 & -0.37 & 0.21 \\
\hline (8) $\beta$ Pos-hss & -1.51 & 0.01 & -3.28 & 0.00 & -0.61 & 0.21 & -0.74 & 0.05 \\
\hline (9) $\beta_{\text {Neg-lss }}$ & -0.16 & 0.61 & -2.18 & 0.00 & -0.13 & 0.75 & 0.10 & 0.76 \\
\hline (10) $\beta_{\text {Neg-hss }}$ & -1.15 & 0.03 & -2.19 & 0.00 & -0.54 & 0.24 & -0.48 & 0.29 \\
\hline \multicolumn{9}{|c|}{$\begin{array}{l}\text { Third criterion: stocks that fulfill the characteristic associated with volatility, as well as, at least, one } \\
\text { additional characteristic. }\end{array}$} \\
\hline (11) $\beta_{\text {Pos-lss }}$ & -0.66 & 0.03 & -0.97 & 0.04 & -0.26 & 0.41 & -0.44 & 0.12 \\
\hline (12) $\beta$ Pos-hss & -2.87 & 0.00 & -2.92 & 0.11 & -1.10 & 0.09 & -1.94 & 0.00 \\
\hline (13) $\beta_{\text {Neg-lss }}$ & -0.11 & 0.73 & -1.31 & 0.01 & -0.87 & 0.03 & -0.83 & 0.04 \\
\hline (14) $\beta_{\text {Neg-hss }}$ & -3.10 & 0.00 & -3.04 & 0.01 & -1.24 & 0.12 & -1.08 & 0.13 \\
\hline \multicolumn{9}{|c|}{ Wald test } \\
\hline $\mathrm{H}_{0}:(3+5) / 2=(4+6) / 2$ & 11.74 & 0.00 & 5.88 & 0.02 & 2.39 & 0.12 & 4.24 & 0.04 \\
\hline $\mathrm{H}_{0}:(7+9) / 2=(8+10) / 2$ & 4.20 & 0.04 & 0.66 & 0.42 & 0.99 & 0.32 & 1.66 & 0.20 \\
\hline $\mathrm{H}_{0}:(11+13) / 2=(12+14) / 2$ & 15.80 & 0.00 & 2.76 & 0.10 & 1.13 & 0.29 & 2.78 & 0.10 \\
\hline
\end{tabular}

Positive and negative analysts' consensus recommendations portfolios for each of the criteria used to define high sentiment sensitivity (HSS) stocks. The explanatory variables are global sentiment, SentG, that is, the composite index that captures the common component in SentUS and SentEU. OLS estimation is used with the Newey and West (1987) standard errors. The coefficients are multiplied by 100. (1) $\beta$ Posall is the effect of investor sentiment on the positive recommendations portfolio; (2) $\beta$ Neg-all is the effect of investor sentiment on the negative recommendations portfolio; (3) $\beta$ Pos-lsss/(4) $\beta$ Pos-hss is the effect of investor sentiment on the positive recommendations of LSS and HSS portfolio, respectively, using the first criterion (volatility); (5) $\beta \mathrm{Neg}$-lss $/(6) \beta \mathrm{Neg}$-hss is the effect of investor sentiment on the negative recommendations of LSS and HSS portfolio, respectively, using the first criterion; (7) $\beta$ Pos-lss $/(8) \beta$ Pos-hss is the effect of investor sentiment on the positive recommendations of LSS and HSS portfolio, respectively, using the second criterion (stocks that fulfill, at least, one of characteristics associated with sentiment sensitivity); 9) $\beta$ Negseguro/(10) $\beta$ Neg-hvda is the effect of investor sentiment on the negative recommendations of LSS and HSS portfolio, respectively, using the second criterion; (11) $\beta$ Pos-lss $/(12) \beta$ Pos-hss is the effect of investor sentiment on the positive recommendations of LSS and HSS portfolio, respectively, using the third criterion (stocks that fulfill the characteristic associated with volatility, as well as, at least, one additional characteristic); (13) $\beta$ Negl-lss/(14) $\beta$ Neg-hss is the effect of investor sentiment on the negative recommendations of LSS and HSS portfolio, respectively, using the third criterion. $\left(\mathrm{H}_{0}\right)$ are the p-values of the Wald test for the null hypothesis of the equality of the coefficients of both the HSS and LSS portfolios for the three criteria used. 
Table VII: Risk-adjusted returns of positive and negative portfolios, 1994-2007.

\begin{tabular}{|c|c|c|c|c|c|c|c|c|}
\hline & \multicolumn{2}{|c|}{ France } & \multicolumn{2}{|c|}{ Germany } & \multicolumn{2}{|c|}{ Spain } & \multicolumn{2}{|c|}{ United Kingdom } \\
\hline & Coef. & p-value & Coef. & p-value & Coef. & $\mathrm{p}$-value & Coef. & p-value \\
\hline \multicolumn{9}{|l|}{ All stocks } \\
\hline (1) $\alpha_{\text {Pos-all }}$ & 0.50 & 0.00 & 0.46 & 0.17 & 0.08 & 0.29 & 0.12 & 0.02 \\
\hline (2) $\alpha_{\text {Neg-all }}$ & -1.14 & 0.00 & -0.99 & 0.00 & -0.25 & 0.14 & -0.45 & 0.01 \\
\hline \multicolumn{9}{|c|}{ First criterion: volatility } \\
\hline (3) $\alpha_{\text {Pos-lss }}$ & 0.66 & 0.00 & 0.78 & 0.01 & 0.35 & 0.09 & 0.31 & 0.04 \\
\hline (4) $\alpha$ Pos-hss & -0.36 & 0.40 & 0.77 & 0.40 & 0.07 & 0.85 & -0.62 & 0.10 \\
\hline (5) $\alpha_{\text {Neg-lss }}$ & -0.41 & 0.09 & -0.34 & 0.64 & 0.41 & 0.27 & -0.08 & 0.65 \\
\hline (6) $\alpha_{\text {Neg-hss }}$ & -2.48 & 0.00 & -1.85 & 0.08 & -0.28 & 0.08 & -1.31 & 0.00 \\
\hline \multicolumn{9}{|c|}{$\begin{array}{l}\text { Second criterion: stocks that fulfill, at least, one of characteristics associated with sentiment } \\
\text { sensitivity }\end{array}$} \\
\hline (7) $\alpha_{\text {Pos-lss }}$ & 0.57 & 0.00 & 0.44 & 0.16 & 0.12 & 0.42 & 0.04 & 0.64 \\
\hline (8) $\alpha_{\text {Pos-hss }}$ & 0.65 & 0.00 & 0.75 & 0.25 & 0.17 & 0.33 & 0.25 & 0.07 \\
\hline (9) $\alpha_{\text {Neg-lss }}$ & -0.77 & 0.00 & -0.89 & 0.04 & 0.11 & 0.72 & 0.05 & 0.83 \\
\hline (10) $\alpha_{\text {Neg-hss }}$ & -1.46 & 0.00 & -1.36 & 0.00 & -0.49 & 0.05 & -0.77 & 0.02 \\
\hline \multicolumn{9}{|c|}{$\begin{array}{l}\text { Third criterion: stocks that fulfill the characteristic associated with volatility, as well as, at least, } \\
\text { one additional characteristic }\end{array}$} \\
\hline (11) $\alpha_{\text {Pos-lss }}$ & 0.61 & 0.00 & 0.43 & 0.22 & 0.39 & 0.12 & 0.23 & 0.20 \\
\hline (12) $\alpha_{\text {Pos-hss }}$ & -0.14 & 0.80 & 0.44 & 0.73 & 0.26 & 0.55 & -0.45 & 0.32 \\
\hline (13) $\alpha_{\text {Neg-lss }}$ & -0.57 & 0.05 & -1.14 & 0.09 & 0.33 & 0.33 & -0.78 & 0.02 \\
\hline (14) $\alpha_{\text {Neg-hss }}$ & -1.69 & 0.03 & -2.42 & 0.02 & -0.52 & 0.19 & -1.59 & 0.00 \\
\hline
\end{tabular}

Positive and negative analysts' consensus recommendations portfolios for each of the criteria used to define high sentiment sensitivity (HSS) stocks. The explanatory variables are global sentiment, SentG, that is, the composite index that captures the common component in SentUS and SentEU. OLS estimation is used with the Newey and West (1987) standard errors. The coefficients are multiplied by 100. (1) $\alpha$ Posall is the risk adjusted return of the positive recommendations portfolio; (2) $\alpha$ Neg-all is the risk adjusted return of the negative recommendations portfolio; $\alpha$ Pos-lsss/(4) $\alpha$ Pos- is the risk adjusted return of the positive recommendations of LSS and HSS portfolio, respectively, using the first criterion (volatility); (5) $\alpha$ Neg-lss/(6) $\alpha$ Neg-hss is the risk adjusted return of the negative recommendations of LSS and HSS portfolio, respectively, using the first criterion; (7) $\alpha$ PosIss/(8) $\alpha$ Pos-hss is the risk adjusted return of the positive recommendations of LSS and HSS portfolio, respectively, using the second criterion (stocks that fulfill, at least, one of characteristics associated with sentiment sensitivity); 9) $\alpha$ Neg-seguro/(10) $\alpha$ Neg-hvda is the risk adjusted return of the negative recommendations of LSS and HSS portfolio, respectively, using the second criterion; (11) $\alpha$ Pos-lss / (12) $\alpha$ Pos-hss is the risk adjusted return of the positive recommendations of LSS and HSS portfolio, respectively, using the third criterion (stocks that fulfill the characteristic associated with the volatility, as well as, at least, one additional characteristic); (13) $\alpha$ Negl-lss/(14) $\alpha$ Neg-hss is the risk adjusted return of the negative recommendations of LSS and HSS portfolio, respectively, using the third criterion. 
Table VIII: Risk-adjusted returns of portfolios with different exposure to investor sentiment, 19942007

\begin{tabular}{lccccccccc}
\multicolumn{1}{c}{ Portfolios } & \multicolumn{2}{c}{ FRANCE } & \multicolumn{2}{c}{ GERMANY } & \multicolumn{2}{c}{ SPAIN } & \multicolumn{2}{c}{ UK } \\
\hline & Coef. & p-value & Coef. & p-value & Coef. & p-value & Coef. & p-value \\
\hline (0) Benchmark & 1.64 & 0.00 & 1.45 & 0.00 & 0.33 & 0.10 & 0.57 & 0.00 \\
\hline First criterion: volatility & & & & & & & & \\
\hline (1) Max.Sent.Exposure & 2.12 & 0.00 & 2.62 & 0.06 & 0.38 & 0.55 & 0.70 & 0.18 \\
(2) Positive skew. & 0.04 & 0.94 & 1.11 & 0.39 & -0.38 & 0.54 & -0.54 & 0.24 \\
(3) Negative skew. & 3.12 & 0.00 & 2.63 & 0.02 & 0.60 & 0.33 & 1.62 & 0.00 \\
(4) Min. Sent. Exposure & 1.06 & 0.00 & 1.11 & 0.08 & -0.06 & 0.90 & 0.39 & 0.07 \\
\hline
\end{tabular}

Second criterion: stocks that fulfill, at least, one of characteristics associated with sentiment sensitivity

\begin{tabular}{lllllllll}
\hline (5) Max. Sent. Exposure & 2.11 & 0.00 & 2.07 & 0.01 & 0.65 & 0.03 & 1.02 & 0.00 \\
(6) Positive skew. & 1.41 & 0.00 & 1.47 & 0.05 & 0.14 & 0.75 & 0.20 & 0.51 \\
(7) Negative skew. & 2.03 & 0.00 & 1.90 & 0.00 & 0.60 & 0.05 & 0.80 & 0.02 \\
(8) Min. Sent. Exposure & 1.34 & 0.00 & 1.41 & 0.02 & 0.04 & 0.89 & -0.01 & 0.95
\end{tabular}

Third criterion: stocks that fulfill the characteristic associated with volatility, as well as, at least, one additional characteristic.

\begin{tabular}{|c|c|c|c|c|c|c|c|c|}
\hline (9) Max. Sent. Exposure & 1.55 & 0.08 & 3.96 & 0.05 & 0.81 & 0.25 & 1.14 & 0.12 \\
\hline (10) Positive skew. & 0.43 & 0.51 & 1.58 & 0.27 & -0.07 & 0.90 & 0.33 & 0.60 \\
\hline (11) Negative skew. & 2.30 & 0.01 & 2.87 & 0.01 & 0.99 & 0.06 & 0.99 & 0.18 \\
\hline (12) Min. Sent. exposure & 1.18 & 0.00 & 1.59 & 0.01 & 0.06 & 0.86 & 1.01 & 0.00 \\
\hline \multicolumn{9}{|c|}{ Wald test } \\
\hline $\mathrm{H}_{0}:(0)=(1)$ & 0.49 & 0.48 & 2.55 & 0.11 & 0.01 & 0.93 & 0.06 & 0.81 \\
\hline $\mathrm{H}_{0}:(0)=(2)$ & 7.61 & 0.01 & 0.08 & 0.77 & 2.36 & 0.12 & 5.73 & 0.02 \\
\hline $\mathrm{H}_{0}:(0)=(3)$ & 4.28 & 0.04 & 2.89 & 0.09 & 2.06 & 0.15 & 4.57 & 0.03 \\
\hline $\mathrm{H}_{0}:(0)=(4)$ & 3.61 & 0.06 & 0.27 & 0.61 & 0.44 & 0.51 & 0.43 & 0.51 \\
\hline $\mathrm{H}_{0}:(1)=(4)$ & 8.06 & 0.00 & 3.16 & 0.08 & 2.96 & 0.09 & 5.81 & 0.02 \\
\hline $\mathrm{H}_{0}:(2)=(3)$ & 1.13 & 0.29 & 0.02 & 0.88 & 0.14 & 0.71 & 3.66 & 0.06 \\
\hline $\mathrm{H}_{0}:(0)=(5)$ & 1.36 & 0.24 & 0.80 & 0.37 & 0.66 & 0.42 & 1.59 & 0.21 \\
\hline $\mathrm{H}_{0}:(0)=(6)$ & 0.36 & 0.55 & 0.00 & 0.98 & 0.14 & 0.71 & 1.36 & 0.24 \\
\hline $\mathrm{H}_{0}:(0)=(7)$ & 1.00 & 0.32 & 0.52 & 0.47 & 0.49 & 0.48 & 0.47 & 0.49 \\
\hline $\mathrm{H}_{0}:(0)=(8)$ & 0.93 & 0.34 & 0.00 & 0.96 & 0.50 & 0.48 & 4.37 & 0.04 \\
\hline $\mathrm{H}_{0}:(5)=(8)$ & 1.80 & 0.18 & 0.30 & 0.58 & 0.72 & 0.39 & 2.27 & 0.13 \\
\hline $\mathrm{H}_{0}:(6)=(7)$ & 0.02 & 0.88 & 0.00 & 0.95 & 0.01 & 0.92 & 0.24 & 0.62 \\
\hline $\mathrm{H}_{0}:(0)=(9)$ & 0.00 & 0.97 & 3.20 & 0.07 & 1.56 & 0.21 & 0.41 & 0.52 \\
\hline $\mathrm{H}_{0}:(0)=(10)$ & 3.01 & 0.08 & 0.62 & 0.43 & 0.34 & 0.56 & 0.49 & 0.49 \\
\hline $\mathrm{H}_{0}:(0)=(11)$ & 2.87 & 0.09 & 3.12 & 0.08 & 1.97 & 0.16 & 3.92 & 0.05 \\
\hline $\mathrm{H}_{0}:(0)=(12)$ & 1.56 & 0.21 & 0.08 & 0.78 & 0.38 & 0.54 & 0.56 & 0.45 \\
\hline $\mathrm{H}_{0}:(9)=(12)$ & 3.66 & 0.06 & 1.81 & 0.18 & 2.19 & 0.14 & 3.93 & 0.05 \\
\hline $\mathrm{H}_{0}:(10)=(11)$ & 0.44 & 0.51 & 0.83 & 0.36 & 0.00 & 0.96 & 0.69 & 0.41 \\
\hline
\end{tabular}

The returns obtained are adjusted by Fama-French factors. OLS estimation is used with the Newey and West (1987) standard errors. Coefficients are multiplied by 100. (1) Maximum exposure portfolio takes the long position in HSS stocks with a positive recommendation and the short position in HSS stocks with a negative recommendation. (2) Positive skewed portfolio takes the long position in HSS stocks with a positive recommendation and the short position in LSS stocks with a negative recommendation. (3) Negative skewed portfolio takes the long position in HSS stocks with a positive recommendation and the short position in LSS stocks with a negative recommendation. (4) Minimum exposure portfolio takes the long position in LSS stocks with a positive recommendation and the short position in LSS stocks with a negative recommendation. Ho: $(0)=(\mathrm{K})$ are the Wald tests for the null hypothesis of equal risk-adjusted return between the self-financing benchmark portfolio (0) and a specific self-financed portfolio (K). Ho: $(J)=(K)$ are the Wald tests for the null hypothesis of equal risk-adjusted return between two specific self-financed portfolios ( $\mathrm{J}$ and $\mathrm{K})$. 
Table IX: Ranking of portfolios with different exposure to investor sentiment 1994-2007

\begin{tabular}{rccccccccc} 
& \multicolumn{2}{c}{ France } & \multicolumn{2}{c}{ Germany } & \multicolumn{2}{c}{ Spain } & \multicolumn{2}{c}{ United Kingdom } \\
\hline & $\mathrm{R}$ & Rank & $\mathrm{R}$ & $\mathrm{Rank}$ & $\mathrm{R}$ & $\mathrm{Rank}$ & $\mathrm{R}$ & Rank \\
\hline Benchmark & 1.64 & 8 & 1.45 & 9 & 0.33 & 9 & 0.57 & 10 \\
\hline Short all Negative Recommendations & 1.14 & 11 & 0.99 & 11 & 0.25 & 11 & 0.45 & 11 \\
Short HSS with Neg Rec (First Crit) & 2.48 & 2 & 1.85 & 8 & 0.28 & 10 & 1.31 & 3 \\
Short HSS with Neg Rec (Sec. Crit) & 1.46 & 10 & 1.36 & 10 & 0.49 & 7 & 0.77 & 8 \\
Short HSS with Neg Rec (Third Crit) & 1.69 & 7 & 2.42 & 5 & 0.52 & 6 & 1.59 & 2 \\
Max Sent. Exp.(First Crit) & 2.12 & 4 & 2.62 & 4 & 0.38 & 8 & 0.70 & 9 \\
Negative Skew.(First Crit) & 3.12 & 1 & 2.63 & 3 & 0.60 & 5 & 1.62 & 1 \\
Max Sent. Exp.(Sec. Crit) & 2.11 & 5 & 2.07 & 6 & 0.65 & 3 & 1.02 & 5 \\
Negative Skew. (Sec. Crit) & 2.03 & 6 & 1.90 & 7 & 0.60 & 4 & 0.80 & 7 \\
Max Sent. Exp. (Third Crit) & 1.55 & 9 & 3.96 & 1 & 0.81 & 2 & 1.14 & 4 \\
Negative Skew.( Third Crit) & 2.30 & 3 & 2.87 & 2 & 0.99 & 1 & 0.99 & 6 \\
\hline
\end{tabular}

The returns (R) obtained are adjusted by Fama-French factors. Coefficients are multiplied by 100 . These coefficients are obtained from Tables VII and VIII. "Short all Negative Recommendations" takes the short position in all stocks with a negative recommendation. "Short HSS with Neg Rec" takes the short position in HSS stocks with a negative recommendation according to the first, second or third criteria, respectively. The Maximum Sentiment exposure portfolio takes the long position in HSS stocks with a positive recommendation and the short position in HSS stocks with a negative recommendation, according to the first, second or third criteria, respectively. The Negative skewed portfolio takes the long position in HSS stocks with a positive recommendation and the short position in LSS stocks with a negative recommendation, according to the first, second or third criteria, respectively 